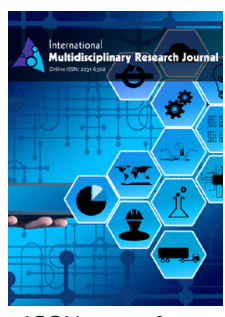

ISSN: $2231-6302$

\title{
Design and Development of a Single-Axis Solar Tracking System
}

\author{
Md. Taslim Mahmud Bhuyain', Robin Kuri², Nayeem Al-Tamzid Bhuiyan³, \\ Md Sahadat Hossain Sagor ${ }^{4}$, Riazul Haidar ${ }^{1 *}$ \\ 'Department of Information and Communication Engineering, Noakhali Science and Technology University, \\ Noakhali - 3814, Bangladesh, 'Department of Digital Media, University of Bremen, 28359 Bremen, Germany, \\ ${ }^{3}$ Department of Electrical and Computer Engineering, North South University, Dhaka - 1229, Bangladesh, \\ 4Department of Information Technologies, Czech University of Life Science, Kamýcká 129, 16521 Prague, Czech \\ Republic
}

\begin{abstract}
With solar tracking, it will become possible to generate more energy since the solar panel can maintain a perpendicular profile to the rays of the sun. Even though the initial cost of setting up the tracking system is considerably high, there are cheaper options that have been proposed over time. This research discuss the design and construction of a prototype for a solar tracking system that has a single axis of freedom. Light Dependent Resistors (LDRs) are used for sunlight detection. The control circuit is based on an ATMega328P microcontroller. It was programmed to detect sunlight via the LDRs before actuating the servo to position the solar panel. The solar panel is positioned where it is able to receive maximum light. As compared to other motors, the servo motors are able to maintain their torque at high speed. They are also more efficient with efficiencies in the range of $80-90 \%$. Servos can supply roughly twice their rated torque for short periods. Through tracking, there will be increased exposure of the panel to the sun, making it have increased power output. The trackers can either be dual or single axis trackers. As a single tracking system is cheaper, less complex, and still achieves the required efficiency, so it was used.
\end{abstract}

*Corresponding Author:

Riazul Haidar

E-mail: riazulrobio1@gmail.com

Received: June 02, 2021

Revised: August 18, 2021

Accepted: August 21, 2021

Published: September 07, 2021

\section{INTRODUCTION}

Energy is the keyword for mankind since everything is revolved around energy. The world population is increasing day by day and the energy demand is increasing accordingly. Fossil fuels and natural gas as the main source of energy nowadays are expected to end up from the world during the recent century which explores a serious problem. For this reason thinking of alternative ways is more important to solve this problem.

Renewable energy or green energy is energy that comes from resources that are continually replenished such as sunlight, wind, rain, tides, waves and geothermal heat. Among the conventional renewable energy sources, solar energy is the most essential and prerequisite resource of sustainable energy. REN2l Global Status Report (2014) pointed out thet renewable energy provided an estimated 19\% of global final energy consumption in 2013 and continued to grow in 2014. Of this total share in 2013, modern renewable accounted for approximately $9 \%$ coming from traditional biomass, $4.2 \%$ from heat energy, $3.8 \%$ from hydropower, and an estimated $2 \%$ was provided by power from wind, solar, geothermal, and biomass, as well as by bio-fuels and are growing very rapidly.
Solar PV has continued to expand at a rapid rate, with growth in global capacity averaging almost 55\% annually over the past five years. Global investment in solar PV declined nearly $22 \%$ relative to 2012 , new capacity installations increased by about $32 \%$. The global solar PV market had a record year, after a brief slowdown, installing more capacity than any other renewable technology except perhaps hydropower. More than $39 \mathrm{GW}$ was added, bringing total capacity to approximately 139 GW (Figure 1).

According to a 2011 projection by the International Energy Agency, solar power generators may produce most of the world's electricity within 50 years, dramatically reducing the emissions of greenhouse gases that harm the environment (Rao, 2019). The primary aim of the research is to design and construct a single-axis tracking mechanism to keep the solar photovoltaic panel perpendicular to the sun throughout the year to make it more efficient.

\section{METHODOLOGY}

The circuit of the solar tracker system is divided into three sections. There is the input stage that is composed of sensors

Copyright: $\odot$ The authors. This article is open access and licensed under the terms of the Creative Commons Attribution License (http://creativecommons.org/licenses/by/4.0/) which permits unrestricted, use, distribution and reproduction in any medium, or format for any purpose, even commercially provided the work is properly cited. Attribution - You must give appropriate credit, provide a link to the license, and indicate if changes were made. 
and potentiometers, a program in embedded software in the microcontroller and lastly the driving circuit that has the servo motor. The input stage has two LDRs that are so arranged to form a voltage divider circuit. AC program loaded into the Atmega 328P forms the embedded software. There is a metallic frame that houses the components. The three stages are designed independently before being joined into one system. This approach, similar to stepwise refinement in modular programming, has been employed as it ensures an accurate and logical approach that is straightforward to understand. This also ensures that if there are any errors, they are independently considered and corrected. The information about designing the whole system including the circuits has been collected from many sources i.e. books, papers, websites, etc. and was studied well to get a better idea. Different techniques have been studied to build a tracking device and to meet user's power requirements. Components have been collected from local markets.

\section{CIRCUIT DIAGRAM}

This system is divided into two categories; hardware and software. The Arduino Uno is a microcontroller board based on the ATmega328. It consumes 14 digital input/output pins (of which 6 can be used as PWM outputs), and 6 analog inputs (Figure 2).

\section{BLOCK DIAGRAM}

The concept of a sun tracking system is quite simple, here light-dependent resistors sense the light intensity and the comparator generates sun-tracking error. Based on this error, it generates the voltage which is used to command the motor driving circuit to drive the low-speed DC motors. That outputs, the rotational speed or displacement of electric motors rotate the solar panel via a speed-reduction system until it perpendicularly faces the sun. A Pulse width modulation (PWM) charge controller is used to charge the battery and to operate a load. The power needed to operate the whole circuit is also provided by this battery. Based on these studies, a preliminary simplified block diagram representations of a solar tracking system is shown in Figure 3.

\section{DESIGN AND IMPLEMENTATION}

\section{Single Axis Solar Tracking System}

Trackers direct solar panels toward the sun. These devices change their orientation throughout the day to follow the sun's path to maximize energy capture. An ideal tracker follows the sun both north-south and east-west. Here a dual-axis solar tracking system was designed and constructed.

\section{Elements of Designed Sun Tracker}

To make an LDR-based dual solar tracking system a variety of electrical components are needed. All the components that were used to develop the tracking system have been discussed in detail in this part. This part of this system is mainly based

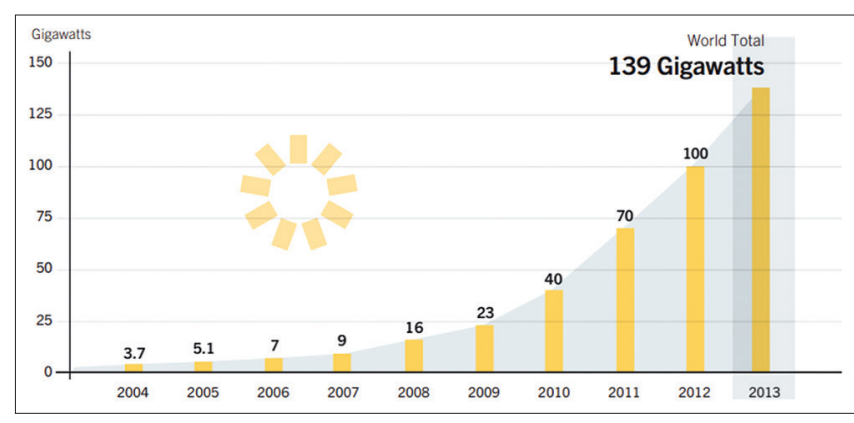

Figure 1: Solar Photovoltaic Total Global Capacity (2004-2013). Source: REN21 Global Status Report (2014)

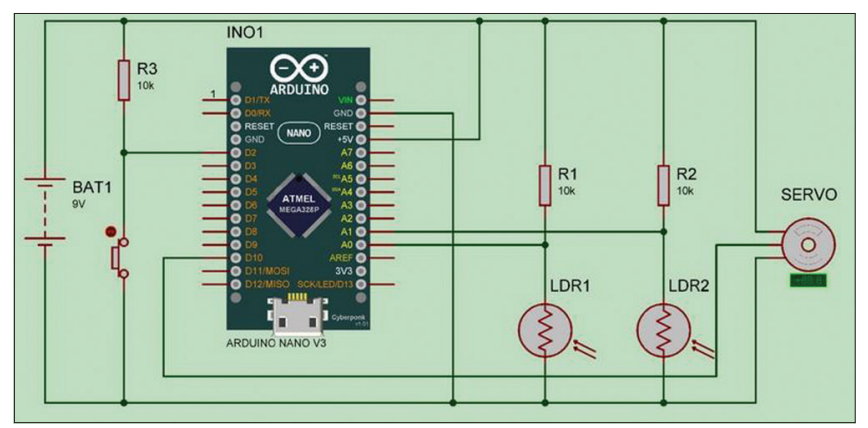

Figure 2: Circuit Diagram

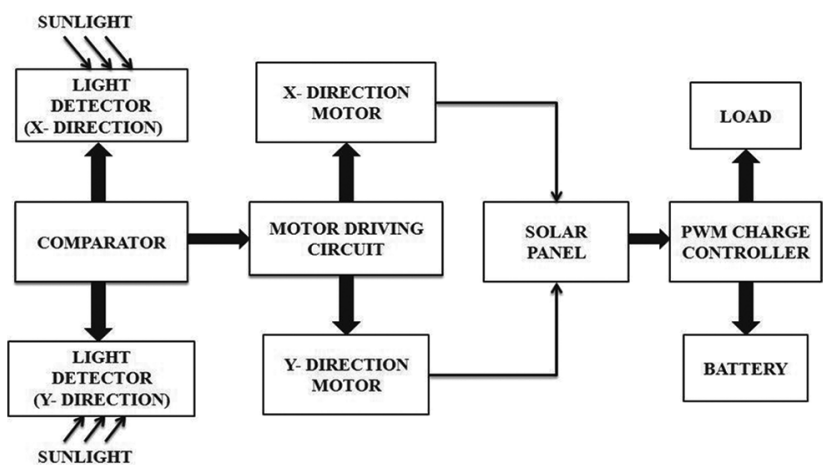

Figure 3: Functional Structure Block Diagram

on the LDR system. The main components of the designed solar tracker consist of, PMDC motor, light-dependent resistor (LDR), positive voltage regulator (IC 7805) as well as few resistors, capacitors and diodes.

\section{Monocrystalline Solar Panel}

A mono-crystalline solar panel has been selected for this system, which is the bulk type silicon. This cell is chosen over the other cells based on cost and the amount of efficiency needed. The multi-junction solar cell is too much expensive, and the thinfilm solar cell is not much reliable. The crystalline type solar cells are the most reliable and commercially available type. Polycrystalline may be cheaper, but the application we're using, would not matter if we used either crystalline solar cell. Monocrystalline is much efficient and provided a sufficient amount of output voltage. The Solar cells are electrically connected and encapsulated as a module with a sheet of glass on top to allow 
light to pass and protect the semiconductor from the weather. To calculate the standard energy of an application, kilowatt-hours per day is used (Figure 4).

\section{Light Sensors (Light Dependent Resistor)}

LDRs are also known as Light-dependent resistor, photovoltaic resistor. A photoresistor or light-dependent resistors (LDR) are light-sensitive resistors whose resistance decreases with increasing incident light intensity and decreases as the intensity of increases; in other words, it exhibits photoconductivity. In the dark, LDR resistance is very high, (it can be $1 \mathrm{M} \Omega$ ) but when the LDR is in light, the resistance drops dramatically (even down to a few ohms) depending on the light intensity (Electrical4U, 2020) (Figure 5).

There are two types of LDR. They are: (a) intrinsic and (b) extrinsic.

a) An intrinsic device has its charge carriers and is not efficient. This type of LDRs is made of high resistance semiconductors. In intrinsic devices, the only available electrons are in the valence band, and hence the photon must have enough energy to excite the electron across the entire bandgap.

b) Extrinsic devices have impurities, also called dopants, and added whose ground state energy is closer to the conduction band; since the electrons do not have as far to jump, lower energy photons are sufficient to trigger the device. These types of LDRs are cadmium supplied. There are very few free electrons when not illuminated or not in

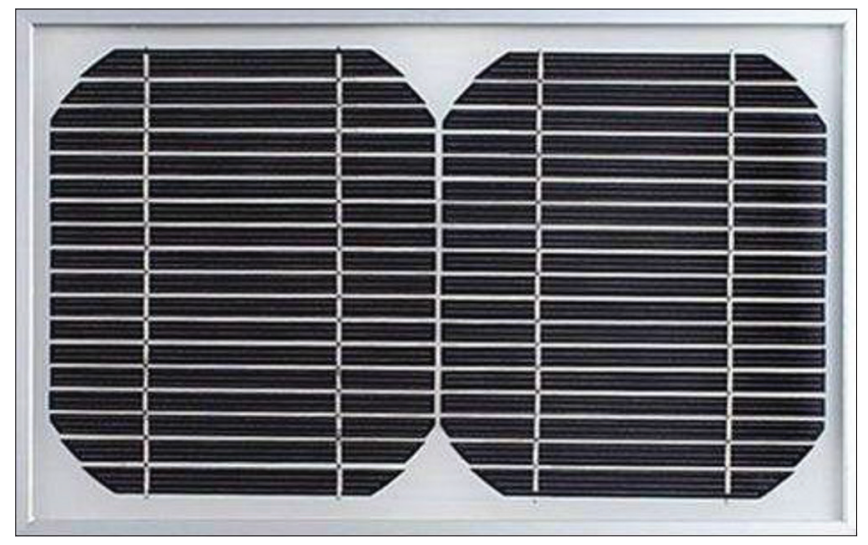

Figure 4: 5W, 18V Monocrystalline Solar Panel

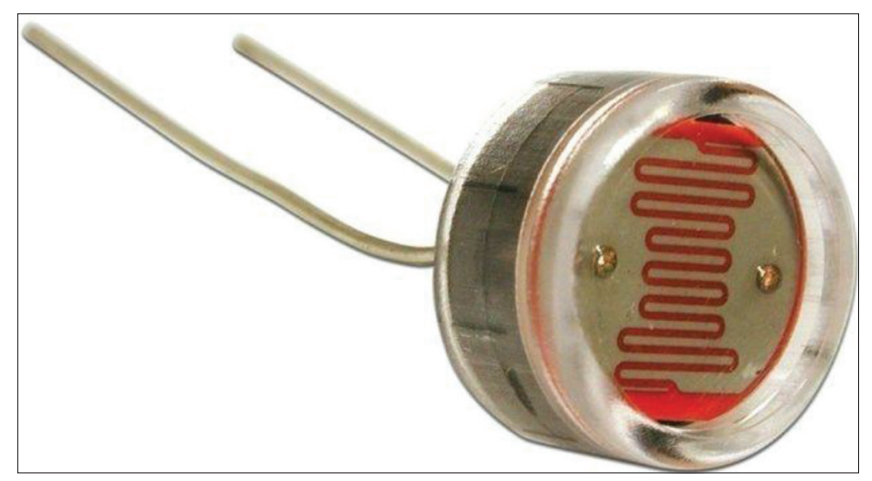

Figure 5: Practical Light Dependent Resistor light. When it absorbs light, electrons are liberated and the conductivity of the material increases. The approximate relationship between the resistance and illumination is:

$$
\mathrm{R}=\mathrm{AE} \sim \mathrm{a}
$$

Where,

$\mathrm{E}=$ Illumination in lux

$\mathrm{R}=$ Resistance in ohms

A, $\mathrm{a}=$ Constant

LDRs are sensitive, inexpensive, and readily available devices. Good in handling power and voltage than other resistance. Their only significant defect is that they are fairly slow-acting, taking tens or hundreds of milliseconds to respond to sudden changes in light level (Electrical4U, 2020).

Useful applications of LDRs are:

- Night Light Control

- Oil Burner Flame Out

- Solar Street Light Control

- Position Sensor

- Camera Exposure Control

- Photocopy Machines - density of toner

- Automatic Gain Control - modulated light source

- Automated Rear View Mirror

- Lead Sulphide (PbS) and Indium Antimonide (InSb) LDRs are used for infrared astronomy and infrared spectroscopy.

\section{Servo Motor}

Servo motors are used for various applications. They are normally small in size and have good energy efficiency. The servo circuitry is built inside the motor unit and comes with a position-able Shaft that is fitted with a gear. The motor is controlled with an electric signal that determines the Amount of shaft movement (Figure 6).

\section{Components of the servo motor}

Inside the servo, there are three main components; a small DC motor, a potentiometer and a control circuit. Gears are used to attach the motor to the control wheel. As the motor rotates, the resistance of the potentiometer changes so the control circuit can precisely regulate the amount of movement there is and the required direction. When the shaft of the motor is at the desired position, the power supply to the motor is stopped. If the shaft is not in the right position, the motor is turned in the right direction. The

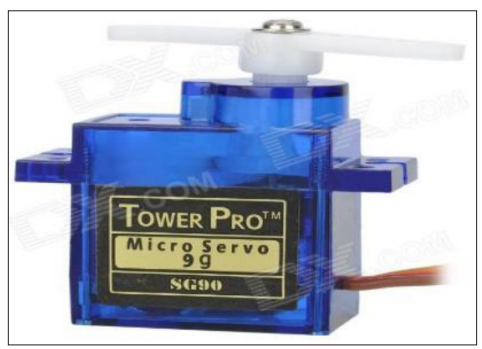

Figure 6: Servo Motor 
desired position is sent through electrical pulses via the signal wire. The speed of the motor is proportional to the difference between the actual position and the position that is desired. Therefore, if the motor is close to the desired position, it turns slowly. Otherwise, it turns fast. This is known as proportional control.

\section{How the servo is controlled?}

Servos are sent through sending electrical pulses of variable width or pulse width modulation (PWM), through the control wire. There is a minimum pulse, maximum pulse and a repetition rate. Servos can usually turn only 90 degrees in either direction for a total of 180 degrees movement. The neutral position of the motor is defined as that where the servo has the same amount of potential rotation in both the clockwise and counter-clockwise direction. The PWM sent to the motor determines the position of the shaft, and based on the duration of the pulse sent through the control wire the rotor will turn to the position that is desired. The servo motor expects to see a pulse every 20 milliseconds and the length of the pulse will determine how far the motor will turn. For instance, a $1.5 \mathrm{~ms}$ pulse makes the motor to turn in the 90 degrees position. If the pulse was shorter than $1.5 \mathrm{~ms}$, it will move to 0 degrees and a longer pulse moves it to 180 degrees. This is shown below.

\section{Advantages and disadvantages of servo motors}

PMDC motor has some advantages over other types of dc motors. They are for applications where high speed and high torque are required, servo motors are the better option. While stepper motors peak at around 2000 RPM, servos are available at much faster speeds. Servo motors also maintain torque at high speed, up to $90 \%$ of the rated torque is available from servos at high speeds. They have an efficiency of about $80-90 \%$ and supply roughly twice their rated torque for short periods. Furthermore, they do not vibrate or suffer from resonance issues.

Servo motors are more expensive than other types of motors. Servos require gearboxes, especially for lower operating speeds. The requirement for a gearbox and position encoder makes the designs more mechanically complex. Maintenance requirements will also increase.

\section{Crystal}

Crystal oscillators are electronic oscillator circuits that use the inverse piezoelectric effect. With this effect, when an electric field is applied across certain materials they will produce mechanical deformation. Therefore a crystal uses the mechanical resonance of a vibrating crystal of piezoelectric material so that there is creation of an electric signal with precise frequency. They have high stability, are low cost and quality factor which makes them superior over such resonators as LC circuits, ceramic resonators and tuning forks.

\section{Voltage regulation}

Voltage regulators are designed to automatically maintain voltages at a constant level. The LM7805 voltage regulator is used. It is a member of the $78 \mathrm{xx}$ series of fixed linear voltage regulator ICs. Voltage sources in circuits could be having fluctuations and thus not be able to give fixed voltage output. The voltage regulator IC maintains the output voltage at a constant value. The LM7805 provides $+5 \mathrm{~V}$ regulated power supply. Capacitors are connected at the input and output depending on respective levels of voltage.

\section{Lead- Acid Battery}

\section{Specification}

- Nominal: Voltage: 12V

- Nominal Capacity: 07Ah

- Charge Voltage Limit: 14.6V

- Discharge Voltage Limit: 12V

- Charging time: 4hrs 6hrs

\section{Main Applications}

Communication: Back-up electric supply, inter-phone.

Electric vehicles: Electric bicycle (E-bike), golf cart, electric wheelchair, E-car and E-bus.

Power tools: Electric cropper, electric drill, electric saw, electric hammer.

Illuminate devices: Solar battery, miner lamp, solar power lamp, emergency light, electric torch.

Video devices: Portable DVD, portable television.

Others: R/C model, toy, small home appliance.

\section{IC LM339N}

LM339 is a comparator IC with four inbuilt comparators. A comparator is a simple circuit that moves signals between the analog and digital worlds. It compares two input voltage levels and gives digital output to indicate the larger one. The two input pins are termed inverting $(\mathrm{V}-)$ and non-inverting $(\mathrm{V}+)$. The output pin goes high when the voltage at $\mathrm{V}+$ is greater than that at V-, and vice versa. In common applications, one of the pins is provided with a reference voltage and the other one receives analog input from a sensor or any external device. If inverting pin ( $\mathrm{V}-$ ) is set as a reference, then $\mathrm{V}+$ must exceed this reference to result in high output. For inverted logic, the reference is set at $\mathrm{V}+$ pin (Figure 7 ).

\section{Features}

- Single or Split Supply Operation

- Low Input Bias Current

- Low Input Offset Current

- Input Common-Mode Voltage Range to GND

- Low Output Saturation Voltage

- TTL and CMOS Compatible. 


\section{Applications}

- Limit Comparators

- Simple A/D Converters

- Pulse/Square wave/Time delay Generators

- Wide Range VCO

- MOS Clock Generator

- High Voltage Digital Logic Gate

- Multi-vibrators

\section{IC L293D}

The L293D is a 16 pin IC, with eight pins, on each side, dedicated to the controlling of a motor. There are 2 INPUT pins, 2 OUTPUT pins and 1 ENABLE pin for each motor (Figure 8).

\section{H-bridge}

H-bridge is given this name because it can be modeled as four switches on the corners of 'H'. The basic diagram of the H-bridge is given below. Using such a circuit, current may be supplied in two directions. The L293D is an H-Bridge with two possible outputs. That means, two things can be connected to it and can be controlled the direction of current flow in both. An $\mathrm{H}$ bridge is an electronic circuit that enables a voltage to be applied across a load in either direction. These circuits are often used in robotics and other applications to allow DC motors to run forwards and backward (Figure 9).

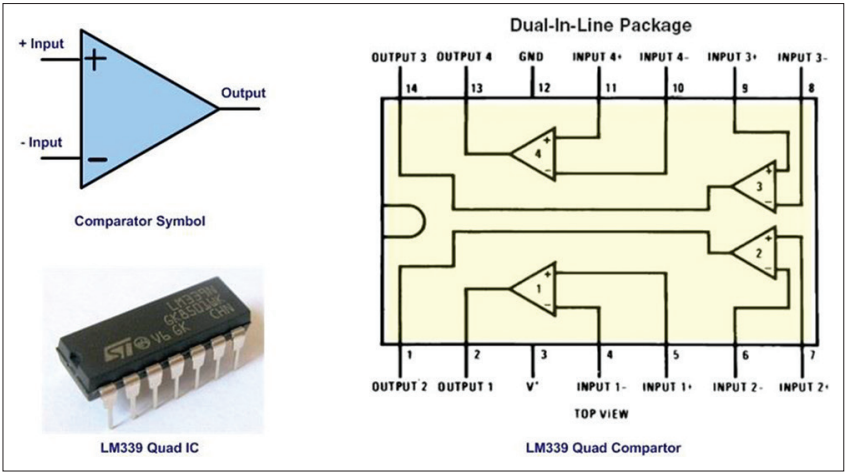

Figure 7: LM339 Quad Comparator (Omar, 2009)

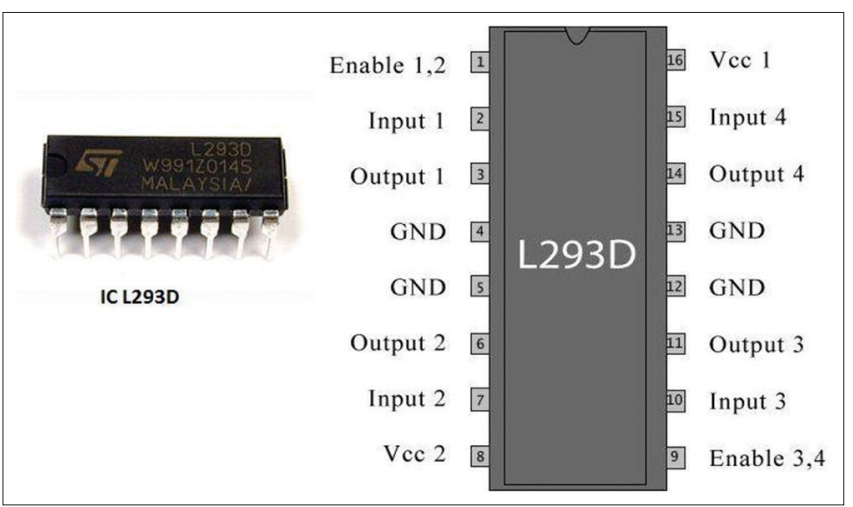

Figure 8: Pin Configuration of ICL293D
An $\mathrm{H}$ bridge is built with four switches. The following table 2 summarizes operation, with S1-S4 corresponding to the diagram above (Electronic Clinic, 2019).

A solid-state $\mathrm{H}$ bridge is typically constructed using opposite polarity devices, such as PNP BJTs or P-channel MOSFETs connected to the high voltage bus and NPN BJTs or N-channel MOSFETs are connected to the low voltage bus.

\section{Designed Single-Axis Solar Tracker Circuit}

\section{PWM solar charge controller}

Power from the solar panel is delivered through the product to the battery system. The controller monitors the battery/system

Table 1: IC LM339 Pin Description

\begin{tabular}{lll}
\hline Pin No. & Function & Name \\
\hline 1 & Output of $2^{\text {nd }}$ comparator & Output 2 \\
2 & Output of $1^{\text {st }}$ comparator & Output 1 \\
3 & Supply voltage $5 \mathrm{~V}$ or $18 \mathrm{~V}$ or 36V & Vcc \\
4 & Inverting input of $1^{\text {st }}$ comparator & Input 1- \\
5 & Non inverting input of $1^{\text {st }}$ comparator & Input 1+ \\
6 & Inverting input of $2^{\text {nd }}$ comparator & Input 2- \\
7 & Non inverting input of $2^{\text {nd }}$ comparator & Input2 + \\
8 & Inverting input of $3^{\text {rd }}$ comparator & Input 3- \\
9 & Non inverting input of $3^{\text {rd }}$ comparator & Input 3+ \\
10 & Inverting input $4^{\text {th }}$ comparator & Input 4- \\
11 & Non inverting input of $4^{\text {th }}$ comparator & Input 4+ \\
12 & Ground (OV) & Ground \\
13 & Output of $4^{\text {th }}$ comparator & Output 4 \\
14 & Output of $3^{\text {rd }}$ comparator & Output 3 \\
\hline
\end{tabular}

Table 2: IC L293D Pin Description

\begin{tabular}{|c|c|c|}
\hline $\begin{array}{l}\text { Pin } \\
\text { No. }\end{array}$ & Function & Name \\
\hline 1 & $\begin{array}{l}\text { When this is HIGH the left part of the IC will work } \\
\text { and when it is low The left part won't work. So, this is } \\
\text { the Master Control pin for the left part of IC }\end{array}$ & S Enable 1-2 \\
\hline 2 & $\begin{array}{l}\text { When this pin is HIGH the current will flow through } \\
\text { output } 1\end{array}$ & INPUT 1 \\
\hline 3 & $\begin{array}{l}\text { This pin should be connected to one of the terminals } \\
\text { of motor }\end{array}$ & OUTPUT 1 \\
\hline 4,5 & Ground pins & GND \\
\hline 6 & $\begin{array}{l}\text { This pin should be connected to one of the terminals } \\
\text { of motor }\end{array}$ & OUTPUT 2 \\
\hline 7 & When this pin is HIGH the current will flow through output 2 & INPUT 2 \\
\hline 8 & $\begin{array}{l}\text { This is the voltage that will be supplied to the motor. } \\
\text { So, if you are driving } 12 \mathrm{~V} \mathrm{DC} \text { motors then make sure } \\
\text { that this pin is supplied with } 12 \mathrm{~V}\end{array}$ & Vcc 2 \\
\hline 9 & $\begin{array}{l}\text { When this is HIGH the right part of the IC will work } \\
\text { and when it is low the right part won't work. So, this } \\
\text { is the Master Control pin for the right part of IC }\end{array}$ & Enable 3-4 \\
\hline 10 & $\begin{array}{l}\text { When this pin is HIGH the current will flow through } \\
\text { output } 3\end{array}$ & INPUT 3 \\
\hline 11 & $\begin{array}{l}\text { This pin should be connected to one of the terminals } \\
\text { of motor }\end{array}$ & OUTPUT 3 \\
\hline 12,13 & 3 Ground pins & GND \\
\hline 14 & $\begin{array}{l}\text { This pin should be connected to one of the terminals } \\
\text { of motor }\end{array}$ & OUTPUT 4 \\
\hline 15 & $\begin{array}{l}\text { When this pin is HIGH the current will flow through } \\
\text { output } 4\end{array}$ & INPUT 4 \\
\hline 16 & $\begin{array}{l}\text { This is the power source of the IC. So, this pin should } \\
\text { be supplied with }\end{array}$ & Vcc 1 \\
\hline
\end{tabular}




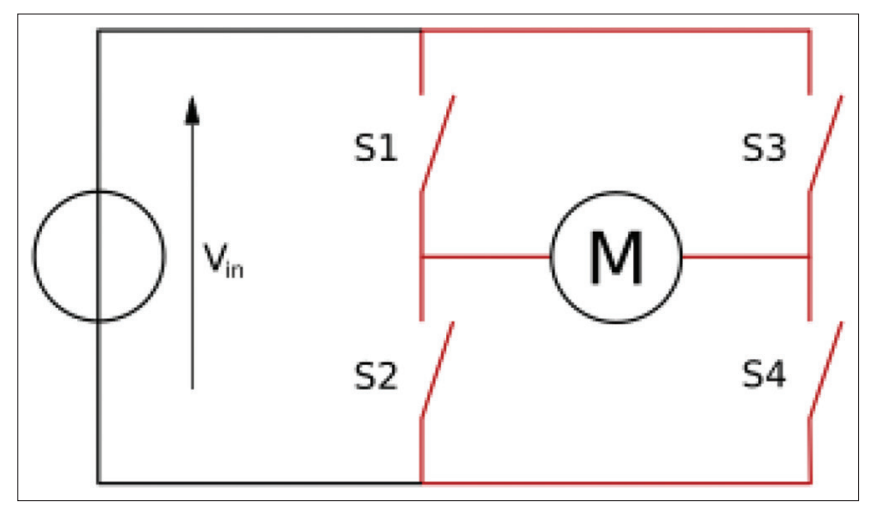

Figure 9: H-Bridge with Two Basic (Electronic Clinic, 2019)

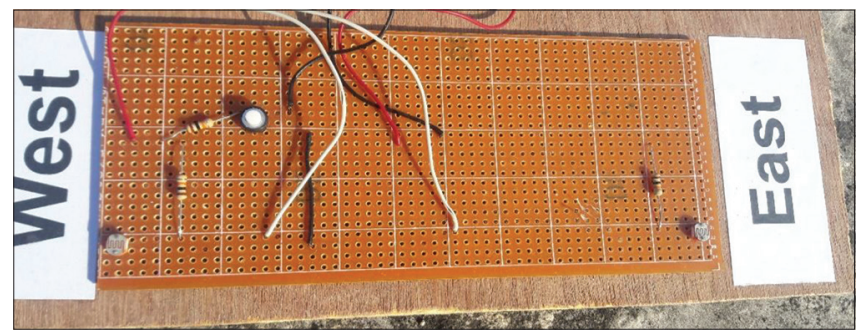

Figure 10: Designed Circuit Diagram of Single Axis Solar Tracker

voltage and supplies power for load consumption and battery charging. If the solar panels are producing excess energy, the controller diverts this un-required energy into the divert resistor. The excess energy is then converted into heat in the resistor. This regulator uses dynamic electronic shunt control. All the available energy is shared between the consumer load, battery charging and dumping. The load consumption is always supplied, followed by the battery requirement. When the battery is fully charged, the regulator "Floats" the battery while continuing to supply the load. Any excess energy is converted to heat and dumped (Figure 11).

\section{IC PIC16F676}

The microcontroller that will be used in this system is PICl6F876A. It is a 14 pin IC. The microcontroller senses both the panel and battery voltages and takes decisions to activate different components of the circuits such as transistors and LED indicators. It is powered up by the lead-acid battery connected to it through a voltage regulator (LM7805) which converts the $12 \mathrm{~V}$ into $5 \mathrm{~V}$. The microcontroller is also powered by a $5 \mathrm{~V}$ supply at pin 1 and ground at pin 14 (Figure 12).

\section{IC P55NF06}

This power MOSFET is the latest development of strip-based process. The resulting transistor shows extremely high packing density for low on-resistance, rugged avalanche characteristics and less critical alignment steps therefore remarkable manufacturing reproducibility. It is mainly used in switching application (Figure 13).
Table 3: H-Bridge Operation

\begin{tabular}{lcccl}
\hline S1 & S2 & S3 & S4 & Result \\
\hline 1 & 0 & 0 & 1 & Motor moves right \\
0 & 1 & 1 & 0 & Motor moves left \\
0 & 0 & 0 & 0 & Motor free runs \\
0 & 1 & 0 & 1 & Motor brakes \\
1 & 0 & 1 & 0 & Motor brakes \\
1 & 1 & 0 & 0 & Shoot-through \\
0 & 0 & 1 & 1 & Shoot-through \\
1 & 1 & 1 & 1 & Shoot-through \\
\hline
\end{tabular}

Table 4: PIC16F676 Pin Description

\begin{tabular}{ll}
\hline Pin No. & Function \\
\hline 1 & Vdd - Positive Power Supply \\
2 & RA5/TICKI/OSCI/CLKIN - Port A \\
3 & RA4/TIG/OSC2/AN3/CLKOUT - Port A \\
4 & RA3/MCLR/Npp - Port A \\
5 & RC5 - Port C \\
6 & RC4 - Port C \\
7 & RC3/AN7 - Port C \\
8 & RC2/AN6 - Port C \\
9 & RC1/AN5 - Port C \\
10 & RCO/AN4 - Port C \\
11 & RA2/AN2/COUT/TOCKI/INT - Port A \\
12 & RAI/AN1/CIN-/Vref/ICSPCLK - Port A \\
13 & RAO/AN0/CIN +/ICSPDAT - Port A \\
14 & VSS - Ground \\
\hline
\end{tabular}

Table 5: IC P55NF06 Pin Description

\begin{tabular}{llc}
\hline Pin No. & Function & Name \\
\hline 1 & Gate voltage & $\mathrm{G}$ \\
2 & Drain Voltage & $\mathrm{D}$ \\
3 & Source Voltage & $\mathrm{S}$ \\
\hline
\end{tabular}

\subsection{IC JC817}

Light-emitting diodes, optically coupled to a phototransistor detector. They are packaged in a 4-pin DIP package and available in wide-lead spacing and SMD option schematic (Figure 14).

\section{Features}

- Current transfer ratio(CTR: $50 \sim 600 \%$ at $\mathrm{IF}=5 \mathrm{~mA}$, $\mathrm{VCE}=5 \mathrm{~V}$ )

- High isolation voltage between input and output (Viso $=5000$ Vrms)

- Creepage distance $>7.62 \mathrm{~mm}$

- Operating temperature up to $+110^{\circ} \mathrm{C}$

- Compact small outline package

- $\mathrm{Pb}$ free and RoHS compliant.

\section{Applications}

- Programmable controllers

- System appliances, measuring instruments

- Telecommunication equipment

- Home appliances, such as fan heaters, etc. 


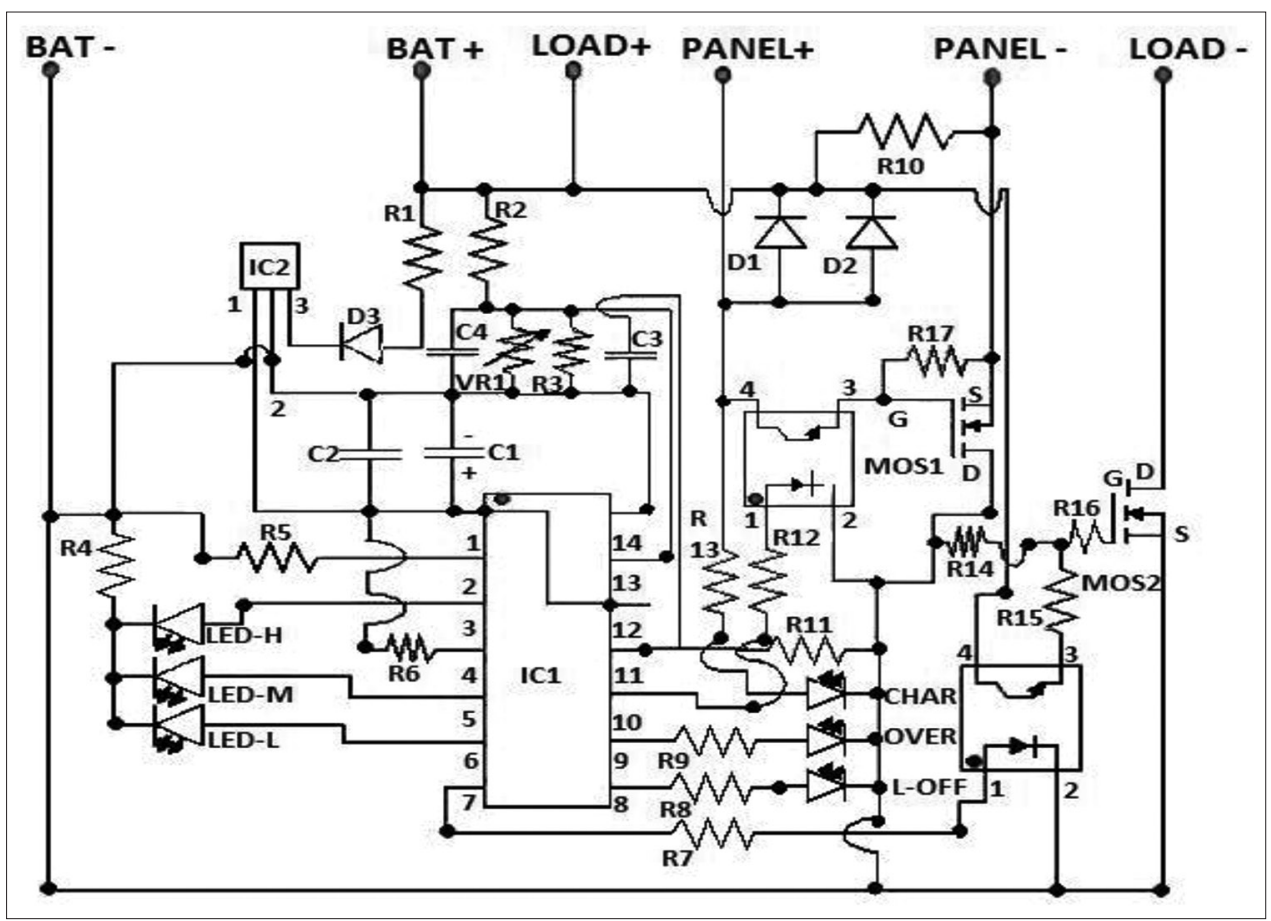

Figure 11: Circuit Diagram of PWM Solar Charge Controller

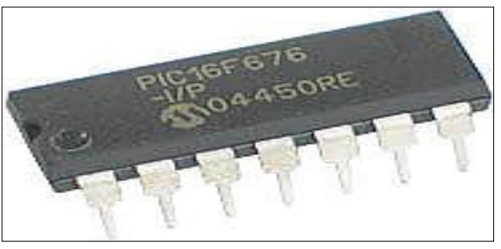

Figure 12: Practical IC PIC16F676

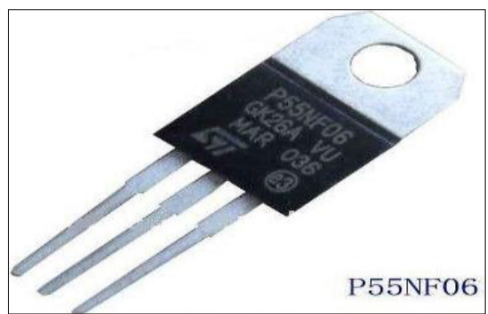

Figure 13: IC P55NF06

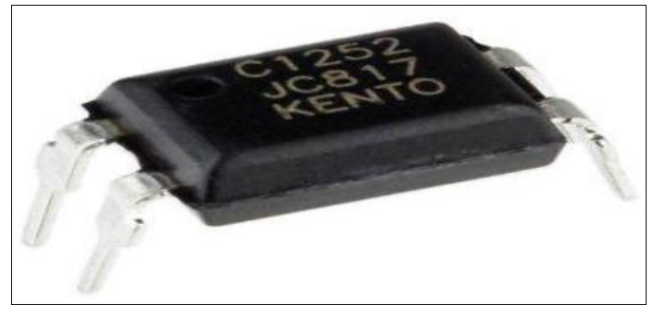

Figure 14: Practical IC JC817

- Signal transmission between circuits of different potentials and impedances

\section{DESIGNED WORKING MODEL OF SINGLE AXIS SOLAR TRACKER USING LIGHT DEPENDENT RESISTOR (LDR) SENSORS}

Experimental Data Analysis

All the theoretical and practical data for fixed position panels and panels with tracking systems has been taken, observed and calculated. All the data collected for the solar system have been included in this.

Dual-Axis Tracking Systems vs. Single-Axis Tracking System and Static Panel

A fixed position panel, a panel with a single-axis tracking system and a panel with a dual-axis tracking system were kept under the sun all day long (From 8 am to 6 pm). The voltage and current were measured from fixed position panel and panel with single-axis and dual-axis tracking device, for these three conditions the power was calculated. After the value was noted, the voltage, power and current were compared with fixed panel and tracking device panels. All the experiments have been conducted in Dhaka, Bangladesh $\left(23^{\circ} 42^{\prime} 00^{\prime \prime} \mathrm{N}, 90^{\circ} 23^{\prime 2} 24^{\prime \prime} \mathrm{E}\right)$ on 15 January 2015. Table 6 shows the current and voltage values received from the static panel, singleaxis tracking system, and dual-axis tracking system for different times in a day. Table 7 shows the power values of the static panel and both the tracking systems. The power gain of tracking systems over the static panels and between the two tracking systems for different times is also given in Table 7. 


\section{Graphical Representations of Static Panel and Tracking Panels}

The graph in Figure 16 shows the voltage levels for static panels, single-axis tracking system and dual-axis tracking systems panels throughout a day. It can be seen from the figure that there has been an increase in voltage levels for the tracking system panel.

The graph in Figure 17 shows the current levels for static panels, single-axis tracking system and dual-axis tracking system panels throughout the day. It can be seen from the figure that the current level has a large increase for the tracking system panels. And panel with tracking maintain peak point of current a large time. It is seen that at 8:00 am there is much improvement in current by both the tracking systems compared to the static panel. But as time goes on the difference in current among these three systems decreases up to around 11:00 am. After that when the sun rotates more towards the west this difference increases again. The highest current of the static panel, singleaxis tracking system, and dual-axis tracking system is $0.21 \mathrm{amp}$, $0.24 \mathrm{amp}$, and $0.249 \mathrm{amp}$, respectively.

The graph in Figure 18 shows the power levels achieved for fixed condition panels, single-axis tracking system and dual-axis tracking system panels throughout a day. That graph indicates that the power level has a large increase for panel for dual-axis tracking system than the steady-state panel and single-axis tracking system.

The average output power is 3.501 for dual-axis solar tracker, 2.958 for single-axis tracker and 2.348 for the static panel. Therefore the average power gain of the solar panel with dualaxis tracking system over fixed conditions is $49.06 \%$. And, the average power gain of the solar panel with dual-axis tracking system over single-axis tracker is $18.32 \%$.

\section{Efficiency Calculation}

Efficiency was calculated theoretically and practically and then static system efficiency and tracking system efficiency were compared.

\section{Theoretical Efficiency}

$$
\begin{aligned}
& \text { Efficiency }=\frac{\text { Maximum power output }}{\text { Incident radiation flux ' Area of collector }} \\
& \text { Here, Area of collector, } A_{C}=0.5833 \mathrm{ft} \text {. ' } 0.8333 \mathrm{ft} \text {. } \\
& =0.486111 \mathrm{ft}^{2} \quad \text { P } 0.045178 \mathrm{~m}^{2} \\
& \text { Incident radiation flux, } \mathrm{E}_{\mathrm{s}, \mathrm{y}}=1000 \mathrm{~W} / \mathrm{m}^{2} \\
& \text { Maximum power output, } \mathrm{P}_{\max }=5 \mathrm{~W} \\
& \text { Efficiency, } h=\frac{5 W}{1000 \frac{w}{m^{2}} \cdot 0.045178 m^{2}} \cdot 100 \% \\
& =0.11067^{\prime} 100 \% \\
& =11.067 \%
\end{aligned}
$$

\begin{tabular}{|c|c|c|c|c|c|c|}
\hline \multirow[t]{2}{*}{ Time } & \multicolumn{3}{|c|}{ Voltage (V) } & \multicolumn{3}{|c|}{ Current $(A)$} \\
\hline & $\begin{array}{l}\text { Static } \\
\text { Panel }\end{array}$ & $\begin{array}{c}\text { Single Axis } \\
\text { Tracking } \\
\text { system }\end{array}$ & $\begin{array}{c}\text { Dual Axis } \\
\text { Tracking } \\
\text { system }\end{array}$ & $\begin{array}{l}\text { Static } \\
\text { Panel }\end{array}$ & $\begin{array}{c}\text { Single Axis } \\
\text { Tracking } \\
\text { system }\end{array}$ & $\begin{array}{c}\text { Dual Axis } \\
\text { Tracking } \\
\text { system }\end{array}$ \\
\hline $\begin{array}{l}\text { 08:00 } \\
\text { am }\end{array}$ & 16.10 & 16.90 & 17.70 & 0.135 & 0.153 & 0.1609 \\
\hline $\begin{array}{l}08: 30 \\
\text { am }\end{array}$ & 16.80 & 17.46 & 18.01 & 0.153 & 0.169 & 0.1933 \\
\hline $\begin{array}{l}09: 00 \\
\mathrm{am}\end{array}$ & 18.65 & 18.69 & 19.70 & 0.175 & 0.190 & 00.191 \\
\hline $\begin{array}{l}09: 30 \\
\text { am }\end{array}$ & 18.90 & 19.70 & 19.70 & 00.18 & 0.196 & 0.2119 \\
\hline $\begin{array}{l}\text { 10:00 } \\
\text { am }\end{array}$ & 18.92 & 19.62 & 19.75 & 00.188 & 00.20 & 0.2292 \\
\hline $\begin{array}{l}10: 30 \\
\mathrm{am}\end{array}$ & 18.97 & 19.67 & 19.76 & 00.19 & 00.203 & 0.2354 \\
\hline $\begin{array}{l}11: 00 \\
\mathrm{am}\end{array}$ & 19.06 & 19.68 & 19.80 & 00.20 & 00.209 & 00.238 \\
\hline $\begin{array}{l}11: 30 \\
\mathrm{am}\end{array}$ & 19.04 & 19.72 & 19.84 & 00.22 & 00.228 & 0.2512 \\
\hline $\begin{array}{l}12: 00 \\
\mathrm{pm}\end{array}$ & 19.17 & 19.90 & 19.90 & 00.23 & 00.228 & 0.2506 \\
\hline $\begin{array}{l}12: 30 \\
\mathrm{pm}\end{array}$ & 18.77 & 19.80 & 19.90 & 00.27 & 00.247 & 0.2507 \\
\hline $\begin{array}{l}\text { 01:00 } \\
\text { pm }\end{array}$ & 18.80 & 19.50 & 19.80 & 00.22 & 0.245 & 0.2551 \\
\hline $\begin{array}{l}\text { 01:30 } \\
\text { pm }\end{array}$ & 18.52 & 19.92 & 19.94 & 00.16 & 00.245 & 0.2498 \\
\hline $\begin{array}{l}\text { 02:00 } \\
\mathrm{pm}\end{array}$ & 18.17 & 19.80 & 19.88 & 00.11 & 00.231 & 00.246 \\
\hline $\begin{array}{l}02: 30 \\
\mathrm{pm}\end{array}$ & 18.01 & 19.58 & 19.70 & 0.082 & 0.153 & 0.2080 \\
\hline $\begin{array}{l}\text { 03:00 } \\
\text { pm }\end{array}$ & 17.32 & 19.38 & 19.68 & 00.0054 & 0.126 & 0.157 \\
\hline $\begin{array}{l}03: 30 \\
\mathrm{pm}\end{array}$ & 17.25 & 19.31 & 19.60 & 0.00401 & 0.060 & 00.152 \\
\hline $\begin{array}{l}\text { 04:00 } \\
\text { pm }\end{array}$ & 16.92 & 18.57 & 19.40 & 00.01 & 0.0432 & 00.116 \\
\hline $\begin{array}{l}\text { 04:30 } \\
\mathrm{pm}\end{array}$ & 16.52 & 18.32 & 19.32 & 0.001 & 0.0338 & 00.074 \\
\hline $\begin{array}{l}\text { 05:00 } \\
\text { pm }\end{array}$ & 16.10 & 17.23 & 18.24 & 0.001 & 0.029 & 00.0541 \\
\hline $\begin{array}{l}05: 30 \\
\mathrm{pm}\end{array}$ & 14.89 & 16.38 & 17.72 & 0.0008 & 0.0124 & 0.0224 \\
\hline $\begin{array}{l}\text { 06:00 } \\
\text { pm }\end{array}$ & 11.92 & 15.04 & 16.80 & 0.0007 & 0.0009 & 0.0176 \\
\hline
\end{tabular}

Table 6: Data table for the values of current and voltage of static panel and single-axis tracking system and dual-axis tracking system panels

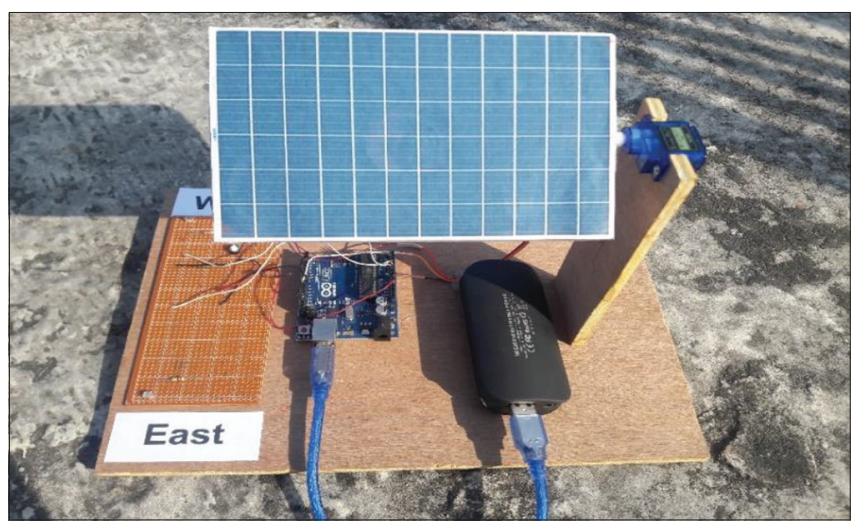

Figure 15: Single-Axis Solar Tracker 
Table 7: Data table for the values of power of static panel and single-axis tracking system and dual-axis tracking system panels and the corresponding power gain by dual-axis tracking system over static panel and single-axis tracking system

\begin{tabular}{|c|c|c|c|c|c|}
\hline \multirow[t]{2}{*}{ Time } & \multicolumn{3}{|c|}{ Power (W) } & \multicolumn{2}{|c|}{ Power gain (\%) } \\
\hline & $\begin{array}{l}\text { Static } \\
\text { panel }\end{array}$ & $\begin{array}{c}\text { Single Axis } \\
\text { Tracking } \\
\text { system }\end{array}$ & $\begin{array}{c}\text { Dual Axis } \\
\text { Tracking } \\
\text { system }\end{array}$ & $\begin{array}{l}\text { Dual Axis } \\
\text { Over } \\
\text { Static panel }\end{array}$ & $\begin{array}{c}\text { Dual Axis Over } \\
\text { Single Axis }\end{array}$ \\
\hline 8:00 am & 2.182 & 2.592 & 2.8491 & 30.57 & 9.92 \\
\hline $8: 30 \mathrm{am}$ & 2.687 & 2.967 & 3.482 & 21.32 & 17.36 \\
\hline $9: 00 \mathrm{am}$ & 3.252 & 3.612 & 3.7628 & 9.003 & 4.17 \\
\hline $9: 30 \mathrm{am}$ & 3.424 & 3.878 & 4.176 & 12.14 & 10.48 \\
\hline 10:00 am & 3.564 & 3.943 & 4.528 & 27.91 & 17.33 \\
\hline $10: 30 \mathrm{am}$ & 3.635 & 3.994 & 4.6527 & 34.76 & 15.66 \\
\hline 11:00 am & 3.8308 & 4.1307 & 4.7134 & 27.21 & 12.36 \\
\hline $11: 30 \mathrm{am}$ & 4.268 & 4.5064 & 4.9852 & 10.37 & 9.203 \\
\hline $12: 00 \mathrm{pm}$ & 4.5257 & 4.5556 & 4.9883 & 9.29 & 9.07 \\
\hline $12: 30 \mathrm{pm}$ & 4.8105 & 4.875 & 4.987 & 1.533 & 0.24 \\
\hline 1:00 pm & 4.282 & 4.853 & 4.9856 & 23.37 & 2.52 \\
\hline $1: 30 \mathrm{pm}$ & 3.024 & 4.875 & 4.9823 & 57.80 & 2.15 \\
\hline 2:00 pm & 2.008 & 4.58 & 4.8909 & 85.13 & 2.26 \\
\hline $2: 30 \mathrm{pm}$ & 1.487 & 2.998 & 4.098 & 77.44 & 35.5 \\
\hline $3: 00 \mathrm{pm}$ & 0.938 & 2.434 & 3.089 & 83.08 & 26.66 \\
\hline $3: 30 \mathrm{pm}$ & 0.692 & 1.1586 & 2.979 & 91.86 & 29.89 \\
\hline 4:00 pm & 0.5034 & 0.8031 & 2.243 & 90.59 & 30.87 \\
\hline 4:30 pm & 0.2664 & 0.6201 & 1.4298 & 88.36 & 33.32 \\
\hline $5: 00 \mathrm{pm}$ & 0.1634 & 0.4988 & 0.9878 & 77.02 & 35.54 \\
\hline $5: 30 \mathrm{pm}$ & 0.1264 & 0.185 & 0.3963 & 96.09 & 36.09 \\
\hline $6: 00 \mathrm{pm}$ & 0.0087 & 0.0137 & 0.2965 & 98.98 & 38.26 \\
\hline $\begin{array}{l}\text { Average } \\
\text { power }\end{array}$ & 2.3485 & 2.958 & 3.5001 & 52.30 & 18.04 \\
\hline
\end{tabular}

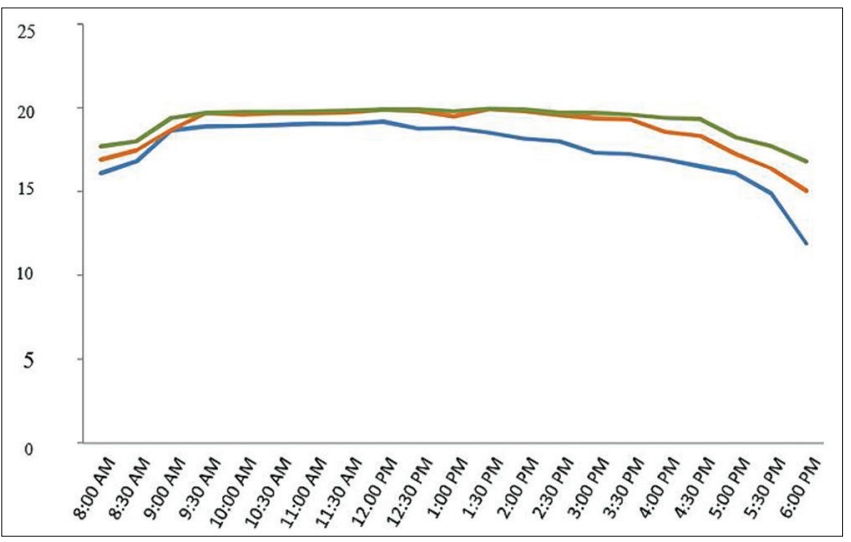

Figure 16: Time vs. Voltage of Static Panel, Single-Axis and Dual-Axis Tracking System

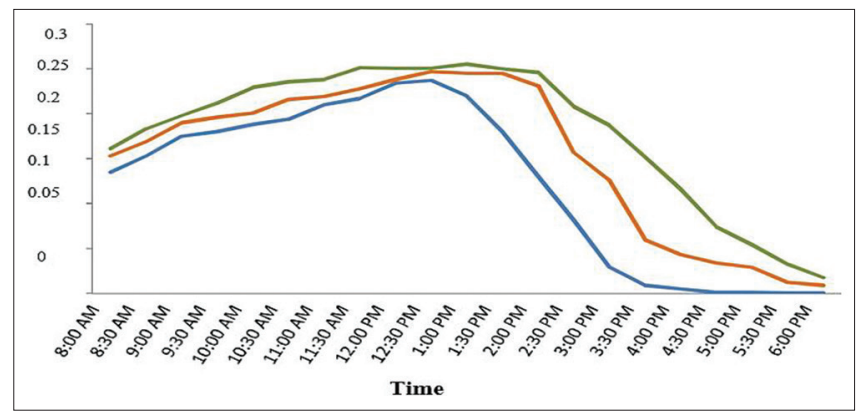

Figure 17: Time vs. Current of Static Panel, Single-Axis and Dual-Axis Tracking System

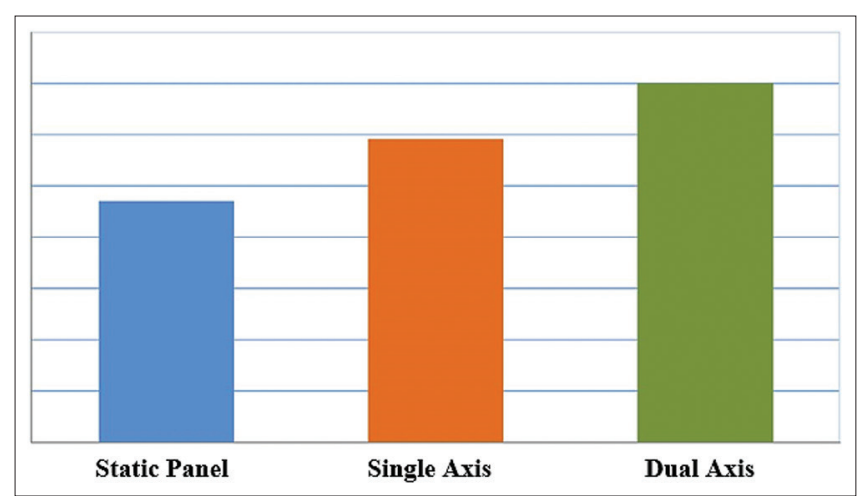

Figure 18: Power Comparisons among Static Panel and Panel with Single-Axis Tracking System and Dual-Axis Tracking System

Practical Efficiency for Static Solar Panel (Peak)

Maximum power output, $\mathrm{P}_{\max (\text { Static })}=4.9105 \mathrm{~W}$

$$
\begin{aligned}
& \text { Efficiency, } h_{\max (\text { Static })}=\frac{4.9105 \mathrm{~W}}{w}{ }^{\prime} 100 \% \\
& 1000-0.045178 \mathrm{~m}^{2} \\
& m^{2} \\
& =0.1086^{\prime} 100 \% \\
& =10.86 \%
\end{aligned}
$$

Practical Efficiency for Static Solar Panel (Average)

Average power output, $\mathrm{P}_{\text {avg (Static) }}=2.348 \mathrm{~W}$

$$
\begin{aligned}
\text { Efficiency, } h_{\text {avg (Static) }} & =\frac{2.348 \mathrm{~W}}{1000-0.045178 \mathrm{~m}^{2}} \cdot 100 \% \\
& =0.0520 \mathrm{~m}^{2} 100 \% \\
& =5.206 \%
\end{aligned}
$$

Practical Efficiency for Single-axis Tracking System (Peak)

Maximum power output, $P_{\max }($ Single Axis) $=4.9750 \mathrm{~W}$

$$
\begin{aligned}
\text { Efficiency, } h_{\max (\text { Single Axis })} & =\frac{4.9750 \mathrm{~W}}{\mathrm{w}}{ }^{\prime} 100 \% \\
& =0.110 \mathrm{~m}^{2} \cdot 100 \% \\
& =11.01 \%
\end{aligned}
$$

Practical Efficiency for Single-axis Tracking System (Average)

Average power output, $\mathrm{P}_{\mathrm{avg}(\text { Single Axis })}=2.958 \mathrm{~W}$ 


$$
\begin{aligned}
\text { Efficiency, } h_{\text {avg(Single Axis) }} & =\frac{2.958 \mathrm{~W}}{w}{ }^{\prime} 100 \% \\
& =0.06547^{\prime} 100 \% \\
& =6.5474 \%
\end{aligned}
$$

\section{Practical Efficiency for Dual-Axis Tracking System (Peak)}

$$
\begin{aligned}
\text { Maximum power output, } & \mathrm{P}_{\max (\text { Dual Axis })}=4.9870 \mathrm{~W} \\
\text { Efficiency, } h_{\max (\text { Dual Axis) }} & =\frac{4.9870 \mathrm{~W}}{\mathrm{w}} \cdot 100 \% \\
& =0.1103 \mathrm{~m}^{2} \cdot 100 \% \\
& =11.038 \%
\end{aligned}
$$

\section{Practical Efficiency for Dual-axis Tracking System} (Average)

$$
\begin{aligned}
& \text { Average power output, } P_{\text {avg (Dual Axis) }}=3.501 \mathrm{~W} \\
& \begin{aligned}
\text { Efficiency, } h_{\text {avg (Dual Axis) }} & =\frac{3.501 \mathrm{~W}}{\mathrm{w}} \cdot 100 \% \\
& 1000-0.045178 \mathrm{~m}^{2} \\
= & 0.07749^{\prime} 100 \% \\
= & 7.749 \%
\end{aligned}
\end{aligned}
$$

Thus can declare that dual-axis solar tracker is slightly more efficient when compared with static panel or single-axis solar tracking system.

\section{DISCUSSION \& CONCLUSION}

According to international public opinion surveys, renewable sources are strongly recommended to promote green energy generation, and solar power is the most promising among them. Thinking in terms of these views as development and favorable weather bases countries the system is a generation of large scale power using "Single Axis Tracking System" which is not yet popular in Bangladesh. This system has been carried out based on solar technologies and the idea of getting more energy using single-axis solar tracking system. The main theme of this system is to generate more electricity using sunlight efficiently and use a PWM charge controller to increase the lifetime of the battery. The system was successfully implemented and the efficiency of solar panels has been maximized and by using single-axis tracking devices. For tracking system device data was taken all day long when the temperature was $27^{\circ}-29^{\circ} \mathrm{C}$ (on a clear sunny day). In this system, when a panel is considered at static state condition the average power consumption is $2.384 \mathrm{~W}$ and single-axis average power consumption is $2.958 \mathrm{~W}$, on the other hand, the average power consumption of dual-axis tracking system is $3.501 \mathrm{~W}$ that shows the better power from static panel and single-axis tracking system. This device helps to increase the efficiency of the solar panel in a great number. And the other important part is the PWM charge controller is used to store the generated power more efficiently to reduce the storing time, battery size and quantity to make the system more reliable and cheaper. This system is a miniature model for large-scale electrical generating system. According to this implementation in the future it can be implemented on large scale in the perspective of Bangladesh. The key purpose was to improve the efficiency of the whole system and reducing the cost and complexity by making it eco-friendly.

\section{REFERENCES}

Electronic Clinic. (2019). Relay H Bridge Driver Circuit, Simulation, and Arduino Programming. [online] Available at: https://www. electroniclinic.com/relay-h-bridge-driver-circuit-simulation-andarduino-programming/. [Accessed 18 June 2021].

Electrical4U (2020). Permanent Magnet DC Motor (PMDC Motor): What is it? (And How Does it Work). [online] Available at: https://www. electrical4u.com/permanent-magnet-dc-motor-or-pmdc-motor/. [Accessed 16 June 2021].

Omar, M. B. (2009). Low cost solar tracker. Thesis, Faculty of Electrical and Electronic Engineering, Universiti Malaysia Pahang.

REN21, P.S. (2014). Renewables 2014: Global Status Report. REN21 Secretariat, Paris, France.

Rao, K. R. (2019). Wind energy for power generation: meeting the challenge of practical implementation. Springer Nature. 


\section{APPENDIXES}

\section{Appendix A: Code used in the Microcontroller}

\#include < Servo.h $>$

Servo tiltServo;

\#define LDRl A0 // LDR 1 pin \#define LDR2 Al // LDR 2 pin

\#define servoPin $9 / /$ servo pin

long sumErrors $=0$; // sum of errors for PID

long wait $=0$; // time between steps

uint8_t lastPosition $=0$; $/ /$ last servo position

int difference $=0$; // difference between the two readings

boolean switchSides = false; // boolean variable to manage

direction of rotation volatile boolean commence = false; //

starts the servo process

void $\operatorname{setup}()\{$

Serial.begin (9600);

tiltServo.attach(servoPin);

attachInterrupt (0, initialize, RISING);

attachInterrupt ( 1 , activateServo, RISING);

\}

void $\operatorname{loop}()\{$

int ldrValuel = analogRead(LDRl); // get analog reading of LDR1 int ldrValue2 = analogRead(LDR2); // get analog reading of LDR2

difference $=1 d r V a l u e l$ - ldrValue2; // calculate difference between the two values if (commence) \{

if (difference $>=-20 \& \&$ difference $<=20)\{$

Serial.println("e");

lastPosition $=$ tiltServo.read () ;

\}

else if (difference $<-20)\{$

if (switchSides) $\{$ sumErrors $=0$;

wait $=0$;

switchSides $=$ false;

\}

tilt(1);

\}

else if (difference $>20)\{$

if (!switchSides) \{

sumErrors $=0$;

wait $=0$;

switchSides = true;

\}

tilt $(0)$;

\}

\}

// Serial.print(“LDRl: “); Serial.println(ldrValuel); // Serial. print(“LDR2: “); Serial.println(ldrValue2);

Serial.print("Difference: “); Serial.println(difference);

// Serial.print(“Sum: “); Serial.println(“sumErrors”);

// Serial.println(“”);

\}

void tilt(boolean flag) \{

int returnInt $=0$; $/ /$ holds PID value

if (flag \&\& tiltServo.read ()$>0)\{/ /$ while servo is more than

0 degrees

tiltServo.write(lastPosition--);
returnInt $=\operatorname{PID}()$;

delay(returnInt);

\}

else if (!flag \&\& tiltServo.read ()$<180)\{/ /$ while servo less than 180 degrees tiltServo.write(lastPosition ++ );

returnInt $=\mathrm{PID}()$;

delay(returnInt);

\}

\}

int $\operatorname{PID}()\{$

wait $=$ abs(difference $)+$ abs(sumErrors); // PI controller.

Assuming $\mathrm{Kp}$ and $\mathrm{Ki}$ are equal to 1 sumErrors + = difference;

// get the integral of errors

return(wait / 300); // return delay value

\}

void initialize ()$\{/ /$ go back to initial position

uint8_t pos $=$ tiltServo.read () ; // get current servo position

for(uint8_t i = pos; pos > 30; pos-- $)\{$

tiltServo.write(pos); // set servo positition

delay $(20)$;

\}

\}

void activateServo( () // activate servo movement

if (commence) commence $=$ false;

else

commence $=$ true;

\}

Appendix B: Code for Obtaining the Results from the LDRs

\#include <EEPROM.h>

\#include $<$ Servo.h $>$

Servo tiltServo;

\#define LDR1 A0 // LDR 1 pin \#define LDR2 Al // LDR 2 pin

\#define servoPin $9 / /$ servo pin

long sumErrors $=0$; // sum of errors for PID

long wait $=0$; / time between steps

uint8 t lastPosition $=0$; / last servo position

int difference $=0$; // difference between the two readings

boolean switchSides = false; // boolean variable to manage

direction of rotation int addr $=0$;

long time $=0$;

int ldrValuel $=0$; int $\operatorname{ldrValue} 2=0$;

void $\operatorname{setup}()\{$

Serial.begin(9600);

tiltServo.attach(servoPin);

attachInterrupt (0, initialize, RISING);

\}

void $\operatorname{loop}()\{$

ldrValuel = analogRead(LDRl); // get analog reading of LDRl

ldrValue2 = analogRead(LDR2); // get analog reading of LDR2

if (addr < 24) logData () ;

difference $=1 \mathrm{drV}$ Valuel $-1 \mathrm{drV}$ alue2; // calculate difference

between the two values if $(\operatorname{digitalRead}(3)==\mathrm{HIGH})\{$

if (difference $>=-20 \& \&$ difference $<=20)\{$

Serial.println("equilibrium”);

lastPosition = tiltServo.read () ;

\} 
else if (difference $<-20)\{$

Serial.println("turn left");

if (switchSides) \{ sumErrors $=0$;

wait $=0$;

switchSides $=$ false;

\}

tilt(1);

\}

else if (difference $>20)\{$

Serial.println("turn right");

if (!switchSides) \{

sumErrors $=0$;

wait $=0$;

switchSides = true;

\}

tilt $(0)$;

\}

// Serial.print(“LDRl: “); Serial.println(ldrValuel); // Serial. print(“LDR2: “); Serial.println(ldrValue2);

Serial.print(“Difference: “); Serial.println(difference);

// Serial.print("Sum: “); Serial.println("sumErrors”);

// Serial.println(“");

\}

void tilt(boolean flag) \{

int returnInt $=0$; $/ /$ holds PID value

if (flag $\& \&$ tiltServo.read ()$>40)\{/ /$ while servo is more than 0 degrees

tiltServo.write(lastPosition--);

returnInt $=\mathrm{PID}()$;

delay(returnInt);

\}

else if (!flag \&\& tiltServo.read ()$<140)\{$ // while servo less than 180 degrees tiltServo.write(lastPosition ++ );

returnInt $=\mathrm{PID}()$;

delay(returnInt);

\}

\}

int $\mathrm{PID}()\{$

wait $=$ abs (difference $)+$ abs(sumErrors $)$; / PI controller.

Assuming $\mathrm{Kp}$ and $\mathrm{Ki}$ are equal to 1 sumErrors $+=$ difference;

// get the integral of errors

return(wait / 300); // return delay value

\}

void initialize ()$\{/ /$ go back to initial position

uint8_t pos = tiltServo.read();// get current servo position

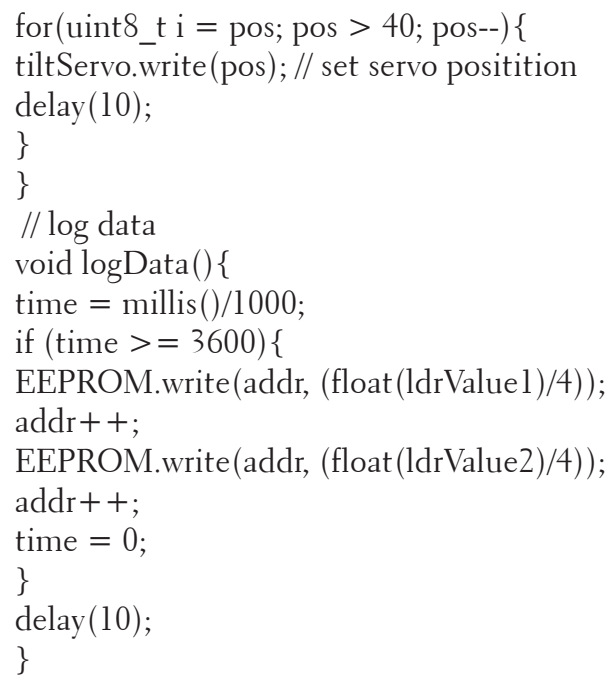

